\title{
Editorial
}

\section{Social Development}

Developmental psychologists think about the past, the present and the future. They think about the past as they wish to understand how characteristics and experiences from an earlier time predict and explain what someone is like now. They are interested in the present as they try to recognize how one's own characteristics are interrelated with one's current circumstances, environments and relationships. Thoughts about the future are aimed at understanding how present levels of functioning interact with experience to predict what someone will be like at a later time.

The papers in this special issue represent these themes in social developmental research. They share a recognition of the multifaceted nature of the social world in which past, present, and future come together to affect well being and outcomes. Each of the papers works in several domains, bringing together concepts or phenomena from one area of functioning (e.g., sex roles and sexual orientation, relations with parents, satisfaction with one's body, and basic features of social functioning) with those from another (e.g., victimization, social competence, academic achievement, the self concept, and metal health). Each paper aims to tell a story about how the personal and the social come together to affect development.

Aside from sharing an attitude about the interaction between contexts and individuals these papers share a memory. Each of these papers was first presented at a small memorial conference for our friend and colleague Lorrie Sippola. Lorrie was interested as a scholar and as a person in the impact of social structures on an individual's past, the present and future. She was especially interested in how the self was the product and the determinant of development. We can imagine that Lorrie would have enjoyed how each of these papers shows how the person's fate is partly determined by who they are and by the part of the social structure where they exist. For those that knew her as a student, a colleague, or a friend, Lorrie will continue to be a part of our past, present, and future.

William M. Bukowski Angela Ittel 